\title{
Protocol Implementation Conformance Statement (PICS) Proforma for the SDNS Security Protocol at Layer 4 (SP4)
}

Wayne A. Jansen

U.S. DEPARTMENT OF COMMERCE Technology Administration National Institute of Standards and Technology Office of Weights and Measures Gaithersburg, MD 20899 



\section{NISTIR 4934}

\section{Protocol Implementation Conformance Statement (PICS) Proforma for the SDNS Security Protocol at Layer 4 (SP4)}

Wayne A. Jansen

U.S. DEPARTMENT OF COMMERCE Technology Administration National Institute of Standards and Technology Office of Weights and Measures Gaithersburg, MD 20899

October 1992

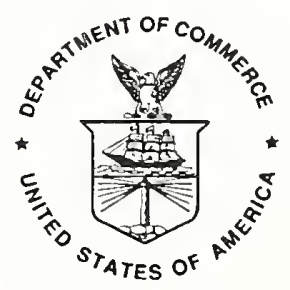

U.S. DEPARTMENT OF COMMERCE Barbara Hackman Franklin, Secretary

TECHNOLOGY ADMINISTRATION

Robert M. White, Under Secretary for Technology

NATIONAL INSTITUTE OF STANDARDS

AND TECHNOLOGY

John W. Lyons, Director 
TABLE OF CONTENTS

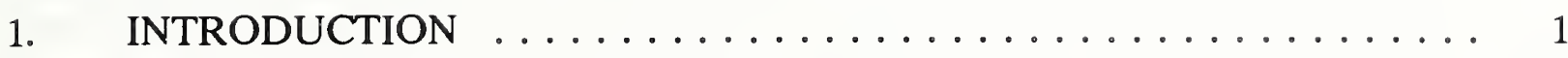

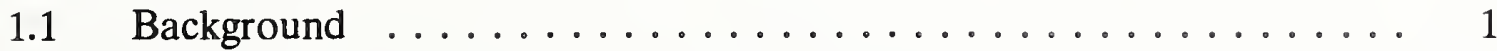

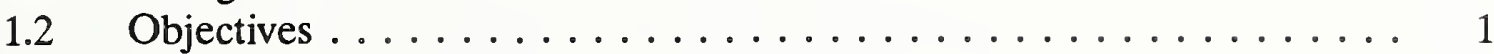

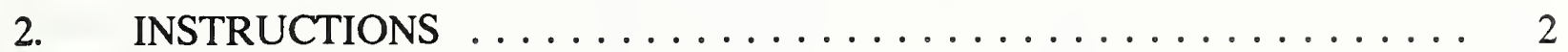

3. IDENTIFICATION $\ldots \ldots \ldots \ldots \ldots \ldots \ldots \ldots \ldots \ldots \ldots \ldots$

4. GENERAL STATEMENT OF CONFORMANCE ........... 3

5. PROTOCOL IMPLEMENTATION .................. 4

6. SECURITY SERVICES SUPPORTED ............... 5

7. SUPPORTED FUNCTIONS $\ldots \ldots \ldots \ldots \ldots \ldots \ldots \ldots \ldots$

8. SUPPORTED PROTOCOL DATA UNITS (PDUs) $\ldots \ldots \ldots \ldots \ldots . . . . .9$

8.1 Supported Transport PDUs (TPDUs) . . . . . . . . . . . . . 9

8.2 Supported Parameters of TPDUs . . . . . . . . . . . . . 9

8.3 Allowed Values of TPDU Parameters $\ldots \ldots \ldots \ldots \ldots \ldots$

9. SUPPORTED ALGORITHMS . . . . . . . . . . . . . . . . 12

10. ERROR HANDLING $\ldots \ldots \ldots \ldots \ldots \ldots \ldots \ldots \ldots \ldots \ldots \ldots$

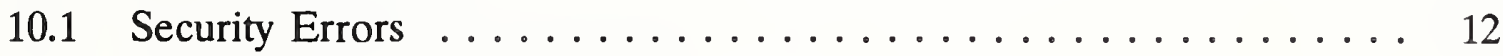

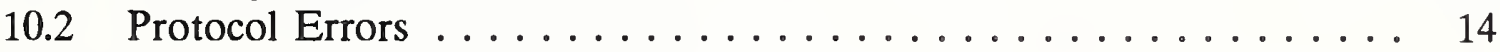

REFERENCES ............................... 15

APPENDIX A: SERVICE, FUNCTION, AND PROTOCOL RELATIONSHIPS 16

A.1 Relationship Between Services and Functions . . . . . . . . . . 17

A.2 Relationship Between Services and Protocol ............. 17 


\begin{abstract}
The Secure Data Network System (SDNS) project, initiated by the National Security Agency in 1986, produced a computer network security architecture within the framework of the International Organization for Standardization (ISO) reference model for Open Systems Interconnection (OSI). The security protocol at layer 4 (SP4) is one element of the SDNS architecture used to provide security services at the Transport Layer of the OSI reference model. This report specifies the Protocol Implementation Conformance Statement (PICS) proforma for SP4. When the PICS proforma is completed for an SP4 implementation, it provides a clear and concise statement of capabilities, useful in a variety of situations to those involved in the production, testing, supply, procurement, and application of the implementation.
\end{abstract}

Key Words: Secure Data Network System; Security Protocol; Protocol Implementation Conformance Statement; Computer Network Security; Open Systems Interconnection; 


\section{INTRODUCTION}

\section{$1.1 \quad$ Background}

The National Institute of Standards and Technology (NIST) and the National Security Agency (NSA) initiated a joint project in Computer Network Security in 1984. The project was based on the recognition that a comprehensive set of security mechanisms is needed to provide cost effective access control to data in geographically distributed computer networks. While the detailed security mechanisms can differ between the classified and unclassified communities requiring security, both communities benefit when commercial computer networks are developed with a common security architecture. The NSA initiated the Secure Data Network System (SDNS) program in 1986 as a result, at least partially, of this joint project.

Security Protocol 4 (SP4) [1,2] is one element of the SDNS architecture [3], used to provide security services at the Transport Layer of the International Organization for Standardization (ISO) Basic Reference Model (BRM) for Open System Interconnection (OSI) [4]. SP4 consists of a simple encapsulation/decapsulation protocol that protects normal Transport Protocol data units within a cryptographically secure envelope. SP4 is compliant with the security addendum to the OSI BRM [5], and forms the basis of the emerging ISO standard for a Transport Layer Security Protocol [6]. SP4 extends the OSI Transport connectionless and connection oriented standards $[7,8]$ to provide or support the following security services defined in the security addendum:
(1) Data Integrity,
(2) Data Confidentiality,
(3) Data Origination Authentication, and
(4) Access Control.

\subsection{Objectives}

This report specifies the Protocol Implementation Conformance Statement (PICS) proforma for SP4. The supplier of a protocol implementation which is claimed to conform to the SDNS Standard [1] shall complete the SP4 PICS proforma. A completed PICS proforma becomes the PICS for the implementation in question. The PICS is a statement identifying the capabilities and options of the protocol that have been implemented. The PICS can serve a number of purposes, including as:

(1) a check list for the protocol implementer, to reduce the risk of failure to conform to the standard through oversight; 
(2) a detailed indication for the supplier and receiver of the implementation of its capabilities, stated relative to the common basis of understanding provided by the standard PICS proforma;

(3) a basis for the user of the implementation to check the possibility of interworking with another implementation;

(4) the basis for a protocol tester to select appropriate tests against which to assess the claim for conformance of the implementation.

The remainder of this report defines the procedures, format, and content that comprise the SP4 PICS proforma. The format is intended to follow the style used in the PICS proforma for the transport protocol [9]. Most of the content is derived directly from the SP4 standard [1]. Appendix A provides the rationale behind the content selection and explores the relationships between services, protocol, and functions.

\section{INSTRUCTIONS}

The first part of the PICS proforma, the Implementation Identification, is to be completed as indicated with the information necessary to identify fully both the supplier and the implementation. The main part of the PICS proforma is a fixed-format questionnaire divided into subclauses, each containing a group of individual items. Answers to the questionnaire items are to be provided in the rightmost column, either by simply marking an answer to indicate a restricted choice (usually "Yes" or "No"), or by entering a value or a set or range of values. Note that there are some items where two or more choices from a set of possible answers can apply. Therefore, all relevant choices are to be marked.

Each item is identified by an reference index in the first column; the second column contains the item to be addressed; the third column contains the reference(s) to the location of the item in the main body of the standard. For optional items, additional columns indicate the status of the item (i.e., whether support is optional, or conditional), and the degree of support for the item (i.e., either a Yes/No indication of support, or space to specify implementation support details).

The following standard PICS proforma notations [10] appear in the status column:

\begin{tabular}{|c|c|}
\hline Symbol & Meaning \\
\hline $\mathrm{m}$ & mandatory \\
\hline o & optional \\
\hline & not applicable (N/A) \\
\hline $0 .<\mathrm{n}\rangle$ & $\begin{array}{l}\text { optional, but support of at least one of the group of options labelled } \\
\text { by the same numeral }\langle n\rangle \text { is required }\end{array}$ \\
\hline
\end{tabular}


Symbol Meaning (continued)

$<$ cid > : conditional requirement, according to the condition or item index identified by <cid >

$<$ item $>$ :: $\quad$ simple predicate condition, dependent on the support marked for $<$ item>

\section{IDENTIFICATION}

Table 1 provides the format for identifying the implementation and its supplier. Only the first three items are required for each implementation. Other information may be completed as appropriate in meeting the requirements for full identification. The terms "Name" and "Version" should be interpreted appropriately to correspond with a supplier's terminology (e.g., using Type, Series, Model).

Table 1: SP4 Implementation Identification

Item

Information

Supplier

Contact point for queries about this PICS

Implementation Name(s) and

Version(s)

Other information necessary for full identification (e.g., Name's and Version(s) for machines and operating systems, System Name(s))

\section{GENERAL STATEMENT OF CONFORMANCE}

Table 2 that follows codifies the general statement of conformance for the implementation. 
Table 2: General Conformance Statement

\begin{tabular}{|c|c|c|c|}
\hline Index & Item & \multicolumn{2}{|c|}{ Support } \\
\hline COTP & $\begin{array}{l}\text { Does the implementation claim } \\
\text { conformance with ISO/IEC } 8073 \text { ? }\end{array}$ & $\mathrm{Y}$ & $\mathrm{N}$ \\
\hline COMAN & $\begin{array}{l}\text { Are all mandatory features of } \\
\text { ISO/IEC } 8073 \text { implemented? }\end{array}$ & $\mathrm{Y}$ & $N$ \\
\hline CLTP & $\begin{array}{l}\text { Does the implementation claim } \\
\text { conformance with ISO/IEC } 8602 \text { ? }\end{array}$ & $\mathrm{Y}$ & $\mathbf{N}$ \\
\hline CLMAN & $\begin{array}{l}\text { Are all mandatory features of } \\
\text { ISO/IEC } 8602 \text { implemented? }\end{array}$ & $\mathrm{Y}$ & \\
\hline SP & $\begin{array}{l}\text { Does the implementation claim } \\
\text { conformance with SDN-401? }\end{array}$ & $\mathrm{Y}$ & $N$ \\
\hline SPMAN & $\begin{array}{l}\text { Are all mandatory features of } \\
\text { SDN-401 implemented? }\end{array}$ & $\mathrm{Y}$ & $\mathrm{N}$ \\
\hline
\end{tabular}

\section{PROTOCOL IMPLEMENTATION}

Table 3 identifies the classes of the connection oriented Transport Protocol (COTP::) supported by the implementation, with regard to their use with either a connection oriented network service (CONS) or a connectionless network service (CLNS).

Table 3: COTP Classes Implemented

$\begin{array}{llcc}\text { Index } & \text { Transport Class } & \text { Support } \\ \text { C0 } & \text { Class } 0 \text { SP4-CONS } & \text { Y } & \text { N } \\ \text { C1 } & \text { Class 1 SP4-CONS } & \text { Y } & \text { N } \\ \text { C2 } & \text { Class 2 SP4-CONS } & \text { Y } & \text { N } \\ \text { C3 } & \text { Class 3 SP4-CONS } & \text { Y } & \text { N } \\ \text { C4 } & \text { Class 4 SP4-CONS } & \text { Y } & \text { N } \\ \text { C4L } & \text { Class } 4 \text { SP4-CLNS } & \text { Y } & \text { N }\end{array}$




\section{SECURITY SERVICES SUPPORTED}

The following set of tables, 4 through 6 , identify for each class of the connection oriented Transport Protocol (COTP::), the security services available through SP4 and their level of support by the implementation. The security services listed are taken from the security addendum to the OSI BRM [2].

Table 4: Service Element Proforma for C0

\begin{tabular}{|c|c|c|c|c|}
\hline Index & Service Element & Status & \multicolumn{2}{|c|}{ Support } \\
\hline TOSE0 & Confidentiality & 0.1 & $\mathrm{Y}$ & \\
\hline T0SE1 & Connection Confidentiality & TOSE0:m & $\mathrm{Y}$ & 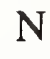 \\
\hline T0SE2 & Connectionless Confidentiality & - & & \\
\hline TOSE3 & Integrity & 0.1 & $\mathrm{Y}$ & 1 \\
\hline TOSE4 & Connection Integrity w Rec & - & & \\
\hline T0SE5 & Connection Integrity wo Recovery & - & & \\
\hline T0SE6 & Connectionless Integrity & TOSE3:m & $\mathrm{Y}$ & \\
\hline TOSE7 & Data Origination Authentication & $\mathrm{m}$ & $\mathrm{Y}$ & $\Lambda$ \\
\hline T0SE8 & Access Control & o & Y & \\
\hline
\end{tabular}

Table 5: Service Element Proforma for C1, C2, C3

\begin{tabular}{|c|c|c|c|c|}
\hline Index & Service Element & Status & \multicolumn{2}{|c|}{ Support } \\
\hline 3SE0 & Confidentiality & 0.1 & $\mathrm{Y}$ & iv \\
\hline T3SE1 & Connection Confidentiality & T3SE0:m & $\mathrm{Y}$ & \\
\hline T3SE2 & Connectionless Confidentiality & - & & \\
\hline T3SE3 & Integrity & 0.1 & $\mathrm{Y}$ & \\
\hline T3SE4 & Connection Integrit & - & & \\
\hline T3SE5 & Connection Integrity wo Recovery & T3SE3:0.2 & $\mathrm{Y}$ & \\
\hline T3SE6 & Connectionless Integrity & T3SE3:0.2 & $\mathrm{Y}$ & \\
\hline T3SE7 & Data Origination Authentication & $\mathrm{m}$ & $\mathrm{Y}$ & \\
\hline T3SE8 & Access Control & o & $\mathrm{Y}$ & $\mathrm{N}$ \\
\hline
\end{tabular}


Table 6: Service Element Proforma for C4, C4L

\begin{tabular}{|c|c|c|c|c|}
\hline Index & Service Element & Status & $\mathrm{Su}$ & \\
\hline T4SE0 & Confidentiality & 0.1 & $\mathrm{Y}$ & $\mathrm{N}$ \\
\hline T4SE1 & Connection Confidentiality & T4SE0:m & $\mathrm{Y}$ & $\mathrm{N}$ \\
\hline T4SE2 & Connectionless Confidentiality & - & & \\
\hline T4SE3 & Integrity & 0.1 & $\mathrm{Y}$ & $\mathrm{N}$ \\
\hline T4SE4 & Connection Integrity w Recovery & T4SE3:0.2 & $Y$ & $\mathrm{~N}$ \\
\hline T4SE5 & Connection Integrity wo Recovery & - & & \\
\hline T4SE6 & Connectionless Integrity & T4SE3:0.2 & $\mathrm{Y}$ & $\mathrm{N}$ \\
\hline T4SE7 & Data Origination Authentication & $\mathrm{m}$ & $\mathrm{Y}$ & $\mathrm{N}$ \\
\hline T4SE8 & Access Control & o & $\mathrm{Y}$ & $\mathrm{N}$ \\
\hline
\end{tabular}

The following table identifies, for the connectionless Transport Protocol (CLTP::), the security services available through SP4 and their level of support by the implementation.

Table 7: Service Element Proforma for CLTP

$\begin{array}{lllll}\text { Index } & \text { Service Element } & \text { Status } & \text { Support } \\ \text { TLSE0 } & \text { Confidentiality } & 0.1 & \mathrm{Y} & \mathrm{N} \\ \text { TLSE1 } & \text { Connection Confidentiality } & - & & \\ \text { TLSE2 } & \text { Connectionless Confidentiality } & \text { TLSE0:m } & \text { Y } & \text { N } \\ \text { TLSE3 } & \text { Integrity } & 0.1 & \mathrm{Y} & \mathrm{N} \\ \text { TLSE4 } & \text { Connection Integrity w Recovery } & - & & \\ \text { TLSE5 } & \text { Connection Integrity wo Recovery } & - & & \\ \text { TLSE6 } & \text { Connectionless Integrity } & \text { TLSE3:m } & \text { Y } & \text { N } \\ \text { TLSE7 } & \text { Data Origination Authentication } & \mathrm{m} & \mathrm{Y} & \mathrm{N} \\ \text { TLSE8 } & \text { Access Control } & \mathrm{o} & \mathrm{Y} & \mathrm{N}\end{array}$




\section{SUPPORTED FUNCTIONS}

The following set of tables, 8 through 13 , identify the mandatory and optional functions implemented for each class of Transport (COTP::) supported.

Table 8: Mandatory Functions for C0

\begin{tabular}{lll}
\hline Index & Function & Ref \\
\hdashline T0F1 & verification of peer address & 6.4 \\
T0F2 & reflection detection & 6.3 .2 \\
T0F3 & security encapsulation & 5.5 \\
T0F4 & reporting of security events & Notes
\end{tabular}

Table 9: Optional Functions for C0

\begin{tabular}{llllll} 
Index & Function & Ref & Status & Support \\
\hdashline T0F5 & data encipherment & 6.2 & 0.1 & Y & N \\
T0F6 & integrity protection & 6.3 & 0.1 & Y & N \\
T0F7 & padding & 6.6 & o & Y & N \\
T0F8 & explicit security labeling & 6.5 & 0 & Y & N
\end{tabular}

Table 10: Mandatory Functions for C1

\begin{tabular}{lll} 
Index & Function & Ref \\
\hdashline T1F1 & verification of peer address & 6.4 \\
T1F2 & reflection detection & 6.3 .2 \\
T1F3 & separation after decapsulation & 6.1 \\
T1F4 & security encapsulation & 5.5 \\
T1F5 & reporting of security events & Notes
\end{tabular}


Table 11: Optional Functions for $\mathrm{C} 1$

Index Function

Ref Status Support

T1F6 data encipherment

$\begin{array}{llll}6.2 & 0.1 & \mathrm{Y} & \mathrm{N}\end{array}$

T1F7 integrity protection

$\begin{array}{llll}6.3 & 0.1 & \mathrm{Y} & \mathrm{N}\end{array}$

T1F8 pre-encapsulation concatenation

$\begin{array}{llll}6.1 & 0 & \mathrm{Y} & \mathrm{N}\end{array}$

T1F9 padding

$\begin{array}{llll}6.6 & 0 & \mathrm{Y} & \mathrm{N}\end{array}$

T1F10 explicit security labeling

$\begin{array}{llll}6.5 & 0 & \mathrm{Y} & \mathrm{N}\end{array}$

Table 12: Mandatory Functions for C2, C3, C4, C4L

\begin{tabular}{|c|c|c|}
\hline Index & Function & Ref \\
\hline T4F1 & verification of peer address & 6.4 \\
\hline $\mathrm{T} 4 \mathrm{~F} 2$ & reflection detection & 6.3 .2 \\
\hline T4F3 & separation after decapsulation & 6.1 \\
\hline $\mathrm{T} 4 \mathrm{~F} 4$ & secure multiplexing & Implicit \\
\hline T4F5 & security encapsulation & 5.5 \\
\hline T4F6 & reporting of security events & Notes \\
\hline
\end{tabular}

Table 13: Optional Functions for C2, C3, C4, C4L

\begin{tabular}{lllll} 
Index Function & Ref & Status & Support \\
\hline T4F7 data encipherment & 6.2 & 0.1 & Y & N \\
T4F8 integrity protection & 6.3 & 0.1 & Y & N \\
T4F9 integrity sequence number & 6.3 .3 & 0 & Y & N \\
T4F10 pre-encapsulation concatenation & 6.1 & o & Y & N \\
T4F11 padding & 6.6 & o & Y & N \\
T4F12 explicit security labeling & 6.5 & o & Y & N \\
T4F13 final sequence number check & 6.3 .3 & o & Y & N
\end{tabular}

Tables 14 and 15 identify the mandatory and optional functions implemented for the connectionless Transport Protocol (CLTP::). 
Table 14: Mandatory Functions for CLTP

\begin{tabular}{lll}
\hline Index & Function & Ref \\
\hline TLF1 & verification of peer address & 6.4 \\
TLF2 & reflection detection & 6.3 .2 \\
TLF3 & security encapsulation & 5.5 \\
TLF4 & reporting of security events & Notes
\end{tabular}

Table 15: Optional Functions for CLTP

\begin{tabular}{llllll} 
Index & Function & Ref & Status & Support \\
\hline TLF5 & data encipherment & 6.2 & 0.1 & Y & N \\
TLF6 & integrity protection & 6.3 & 0.1 & Y & N \\
TLF7 padding & 6.6 & 0 & Y & N \\
TLF8 & explicit security labeling & 6.5 & 0 & Y & N
\end{tabular}

\section{SUPPORTED PROTOCOL DATA UNITS (PDUs)}

\subsection{Supported Transport PDUs (TPDUs)}

As indicated in Table 16, the security encapsulation (SE) TPDU is supported for both transmission and receipt, for the connectionless Transport Protocol (CLTP::) and all classes of the connection oriented (COTP::).

Table 16: TPDUs Supported

Index TPDU Item
ST1 SE
ST2

\subsection{Supported Parameters of TPDUs}

Tables 17 and 18 indicate which parameters are mandatory or optional when a SE TPDU is issued by Transport (COTP:: or CLTP::). 
Table 17: Mandatory Parameters for COTP, CLTP

\begin{tabular}{lll} 
Index & Parameter & Ref \\
\hdashline SPI1 & Key Identifier must be present. & $6.2,6.3$ \\
SPI2 & Bit one of Protected Header Flag must & 8.2 .2 .2 \\
& be set as direction indicator.
\end{tabular}

Table 18: Optional Parameters for COTP, CLTP

\begin{tabular}{|c|c|c|c|c|}
\hline Index & Parameter & Ref & Status & Support \\
\hline SPI3 & Label & 8.2 .2 & o & Y \\
\hline SPI4 & $\mathrm{Pad}$ & 8.2 .2 & o & Y \\
\hline SPI5 & FSN & 8.2 .3 & o & Y \\
\hline SPI6 & ICV & 8.2 .4 & o & Y \\
\hline
\end{tabular}

Transport implementations (COTP:: or CLTP::) shall be capable of receiving and processing all possible parameters of the SE TPDU as indicated in Table 19.

Table 19: Mandatory Parameters for COTP, CLTP

\begin{tabular}{|c|c|c|}
\hline Index & Parameter & Ref \\
\hline SPR1 & Key Identifier must be present. & 6.2 \\
\hline SPR2 & $\begin{array}{l}\text { Bit one of Protected Header Flag must } \\
\text { be set as direction indicator. }\end{array}$ & \\
\hline SPR3 & Label & 8.2 .2 \\
\hline SPR4 & $\mathrm{Pad}$ & 8.2 .2 \\
\hline SPR5 & FSN & 8.2 .2 \\
\hline SPR6 & ICV & 8.2 .4 \\
\hline
\end{tabular}




\subsection{Allowed Values of TPDU Parameters}

The following tables indicate the allowed range of values or size of value representation for the parameters of issued or received TPDUs, for the connectionless Transport Protocol (CLTP::) and all classes of the connection oriented (COTP::).

Table 20: Values for Parameters of Issued TPDUs for COTP, CLTP

\begin{tabular}{|c|c|c|c|}
\hline & & Allowed & Supported \\
\hline AVI1 & Key Identifier & \multirow{2}{*}{$\begin{array}{l}1-254 \text { octets } \\
\text { "0" or "1" }\end{array}$} & \\
\hline AVI2 & $\begin{array}{l}\text { Prot Header Flags } \\
\text { Label }\end{array}$ & & \\
\hline AVI3 & Defining Authority & 1 octet & \\
\hline AVI4 & Value & $1-\mathrm{m}$ octets & \\
\hline AVI5 & $\begin{array}{l}\text { Padding } \\
\text { Length }\end{array}$ & "1" to "254" & \\
\hline AVI6 & Value & 1-254 octets & \\
\hline AVI7 & ICV & 1-indef octet & \\
\hline
\end{tabular}

Table 21: Values for Parameters of Received TPDUs for COTP, CLTP

Allowed Supported

AVR1 Key Identifier

AVR2 Prot Header Flags

Label

AVR3 Defining Authority

AVR4 Value

Padding

AVR5 Length

AVR6 Value

AVR7 ICV

$1-254$ octets
"0" or "1"
1 octet
$1-\mathrm{m}$ octets
"1" to "254"
$1-254$ octets
1 -indef octets


Note: Field sizes for the parameters of the protected header must meet the following length restrictions for TPDUs issued and received: $20+(m+2)+($ Length +2$)<=254$ octets.

\section{SUPPORTED ALGORITHMS}

Table 22 identifies the set of confidentiality and integrity algorithms supported by the implementation.

Table 22: Supported Algorithms

\begin{tabular}{lll} 
Index Item & Ref & Algorithm Identifier(s) \\
\hline ALG1 Data Encryption & 6.2 .3 & \\
ALG2 MAC ICV & 6.3 .1 .3 & \\
ALG3 MDC ICV & 6.3 .1 .3 & \\
& & \\
\end{tabular}

\section{ERROR HANDLING}

\subsection{Security Errors}

Tables 23 and 24 contain the mandatory and optional security error actions to be taken upon receipt of an SE TPDU corresponding to the event description. In addition, all mandatory actions require that the security relevant event be reported to systems management. 
Table 23: Mandatory Security Error Actions for COTP, CLTP

Index Event

Ref

SER1 An improperly protected TPDU received shall

6.0 be discarded.

SER2 A TPDU with an invalid key identifier shall be discarded.

SER3 A TPDU with an invalid ICV shall be discarded. 6.3.1.3

SER4 A TPDU with an invalid direction indicator shall be discarded.

SER5 A TPDU with an improper label shall be discarded. 6.5.3

SER6 A TPDU with an improper pad shall be discarded.

SER7 A TPDU with a duplicate sequence number shall

6.3.3.1.2 be discarded.

SER8 A TPDU with an invalid peer address shall be discarded.

Notes: a) In item SER1, an improperly protected TPDU includes both those SE TPDUs where non-negotiated options are used, and those where negotiated options are not used.

b) Item SER7 applies only to the connection oriented Transport Protocol (COTP::) when integrity sequence number space and truncation protection have been negotiated for $\mathrm{C}$, C3, C4, or C4L.

Table 24: Optional Security Error Actions for COTP, CLTP

Action

Allowed Supported

SER9 An invalid final sequence number detected for an encapsulated DR, DC, or ER TPDU.

SER10 An invalid destination address, inconsistent with that negotiated for the associated key identifier, appears on an encapsulated TPDU.

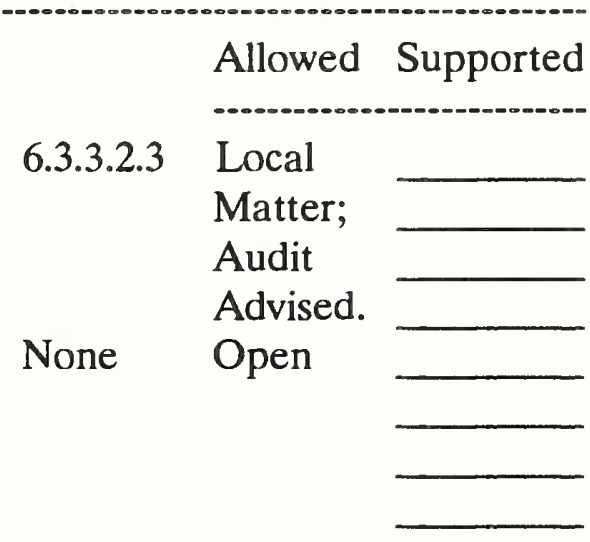


Note: Item SER9 applies only to the connection oriented Transport Protocol (COTP::) when integrity sequence number space and truncation protection have been negotiated for $\mathrm{C} 2, \mathrm{C} 3, \mathrm{C} 4$, C4L.

\subsection{Protocol Errors}

Table 25 identifies the protocol error actions to be taken upon receipt of an SE TPDU corresponding to the event description.

Table 25: Protocol Error Actions for COTP, CLTP

\begin{tabular}{|c|c|c|c|c|}
\hline \multicolumn{2}{|c|}{ Index Event } & \multirow[t]{2}{*}{ Ref } & \multicolumn{2}{|c|}{ Action } \\
\hline & & & Allowed & Supported \\
\hline PER1 & $\begin{array}{l}\text { An undefined parameter } \\
\text { encountered in the protected } \\
\text { header. }\end{array}$ & None & Open & \\
\hline PER2 & $\begin{array}{l}\text { Protected header parameters } \\
\text { discovered out of sequence. }\end{array}$ & None & Open & \\
\hline PER3 & $\begin{array}{l}\text { FSN parameter appears in } \\
\text { the protected header of an } \\
\text { encapsulated TPDU, other } \\
\text { than DR, DC, or ER. }\end{array}$ & None & Open & \\
\hline
\end{tabular}




\section{REFERENCES}

[1] Specification SDN.401, Secure Data Network Systems (SDNS) Security Protocol 4 (SP4), revision 1.3, National Security Agency, May 1989.

[2] D. Branstad and others, SP4: A Transport Encapsulation Security Protocol, Proceedings National Computer Security Conference, Sept. 1987.

[3] R. Nelson, SDNS Services and Architecture, Proceedings National Computer Security Conference, Sept. 1987.

[4] ISO IS 7498, Open systems Interconnection - Basic Reference Model, 1984.

[5] ISO IS 7498/2, Open Systems Interconnection Reference Model - Security Architecture, 1988.

[6] ISO/IEC DIS 10736, Draft International Standard - OSI Transport Layer Security Protocol, October 11, 1991.

[7] ISO IS 8602, Information Processing Systems - Open Systems Interconnection Protocol for Providing the Connectionless Mode Transport Service, 1987.

[8] ISO IS 8073, Information Processing Systems - Open Systems Interconnection Connection Oriented Transport Protocol Specification, 1988.

[9] ISO/IEC JTC 1/SC6 N5839, Third Revised Text of ISO/IEC 8073 PDAD 3.2: Connection Oriented Transport Protocol Specification - Addendum 3: Protocol Implementation Conformance Statement Proforma, July 31990.

[10] ISO/IEC JTC 1/SC6 N6233, Catalogue of PICS Proforma Notations, October 15, 1990. 


\section{APPENDIX A: SERVICE, FUNCTION, AND PROTOCOL RELATIONSHIPS}

The SP4 standard poses a bit of a paradox. Its presentation is simple, yet a high degree of complexity arises when considering its use with the connectionless Transport protocol and the various classes of the connection oriented Transport protocol, in light of the available options. This complexity becomes more evident in the PICS proforma, since the full capabilities of the protocol must be expressed. Perhaps the hardest area of the proforma to reconcile is the SP4 service elements. This is due in large part to the somewhat weak service elements definitions appearing in the security addendum to the OSI reference model. The following guidelines are provided as an aid to understanding:

(1) Connection confidentiality is indicated when the Transport service is connection oriented and the TPDUs are protected accordingly.

(2) Connectionless confidentiality is indicated when the Transport service is connectionless and the TPDUs are protected accordingly.

(3) Connection integrity is indicated when the Transport service is connection oriented, and the integrity sequence number space and per connection key granularity options are in effect. If recovery procedures are included in the Transport class then connection integrity with recovery applies.

(4) Connectionless integrity is indicated when either

(a) the Transport service is connectionless, or

(b) the Transport service is connection oriented, the integrity sequence number space option is not in effect, and the per end-system key granularity option is in effect.

(5) Data origination authentication is implicit since a pair-wise key shared between entities is used to decrypt or verify the integrity check value on an incoming security encapsulated TPDU.

(6) Access control is indicated whenever security labels are employed and/or other access controls associated with the cryptographic association have been implemented.

Once the service elements have been resolved, the remainder of the PICS proforma is easier to digest. In particular, the underlying support functions and protocol may be mapped directly from the SP4 security services. The following sections explain these relationships in detail. 


\section{A.1 Relationship Between Services and Functions}

Table 26 below gives a mapping between OSI security services provided by SP 4 and the associated functions needed in an implementation. The consistency between supported functions and security services shall be maintained accordingly.

Table 26: Mapping of Security Services to Supported Functions

\begin{tabular}{|c|c|}
\hline Security Service & Functions \\
\hline Confidentiality & $\begin{array}{l}\text { data encipherment } \\
\text { padding }\end{array}$ \\
\hline Connection Integrity & $\begin{array}{l}\text { integrity sequence number space } \\
\text { integrity protection } \\
\text { reflection detection } \\
\text { final sequence number check } \\
\text { padding }\end{array}$ \\
\hline Connectionless Integrity & $\begin{array}{l}\text { integrity protection } \\
\text { reflection detection } \\
\text { padding }\end{array}$ \\
\hline Data Orig. Authentication & $\begin{array}{l}\text { verification of peer address } \\
\text { security encapsulation } \\
\text { use of either: } \\
\text { integrity protection } \\
\text { or data encipherment }\end{array}$ \\
\hline Access Control & $\begin{array}{l}\text { explicit security labeling } \\
\text { secure multiplexing } \\
\text { security encapsulation }\end{array}$ \\
\hline
\end{tabular}

\section{A.2 Relationship Between Services and Protocol}

Table 27 gives a mapping between OSI security services provided by SP4 and the SE TPDU protocol control information (PCI) and parameter fields employed by the underlying security mechanisms. The consistency between supported security parameters and SE TPDU parameter fields shall be maintained accordingly. 
Table 27: Mapping of Security Services to SE TPDU Parameters

\begin{tabular}{|c|c|}
\hline Security Service & TPDU Parameters/PCI \\
\hline Confidentiality & $\begin{array}{l}\text { encrypted data } \\
\text { pad }\end{array}$ \\
\hline Connectionless Integrity & $\begin{array}{l}\text { integrity check value } \\
\text { direction indicator } \\
\text { pad }\end{array}$ \\
\hline Connection Integrity & $\begin{array}{l}\text { integrity check value } \\
\text { direction indicator } \\
\text { DT/ED send sequence number } \\
\text { final sequence number } \\
\text { pad }\end{array}$ \\
\hline Data Orig. Authentication & $\begin{array}{l}\text { peer address } \\
\text { key identifier } \\
\text { key identifier employed in: } \\
\text { integrity check value } \\
\text { or encrypted data }\end{array}$ \\
\hline Access Control & $\begin{array}{l}\text { security label } \\
\text { key identifier } \\
\text { key identifier employed in: } \\
\text { integrity check value } \\
\text { or encrypted data }\end{array}$ \\
\hline
\end{tabular}




\begin{tabular}{|c|c|}
\hline \multirow{3}{*}{$\begin{array}{l}\text { U.S. DEPARTMENT OF COMMERCE } \\
\text { NATIONAL INSTITUTE OF STANDARDS AND TECHNOLOGY } \\
\text { BIBLIOGRAPHIC DATA SHEET }\end{array}$} & $\begin{array}{l}\text { 1. PUELCATION OR REPORT MULEER } \\
\text { NISTIR } 4934\end{array}$ \\
\hline & 2 PERFORMIMQ ORCANIZZTION REPOAT MUMEER \\
\hline & $\begin{array}{l}\text { P. PUBUCATIOHDATE } \\
\text { OCTOBER } 1992\end{array}$ \\
\hline \multicolumn{2}{|l|}{ Q. TIUEAND SUDTIUE } \\
\hline $\begin{array}{l}\text { Protocol Implementation Conformance Statement (PICS) Proforma } \\
\text { at Layer } 4 \text { (SP4) }\end{array}$ & for the SDNS Security Protocol \\
\hline \multicolumn{2}{|l|}{ 5. AUTHOA(S) } \\
\hline \multicolumn{2}{|l|}{ Wayne A. Jansen } \\
\hline Q. PERFORMIMO ORQANRETION (IF JOINT OR OTHER TMAN MIST, SEE INSTRUCTIONS) & 7. CONTRACT/CRANT MUMBEA \\
\hline $\begin{array}{l}\text { U.S. DEPANTMEATT OF COMMERCE } \\
\text { MATIONAL IMSTITUTE OF STANDARDS AND TECHNOLOOY } \\
\text { GNTHERSEURG, MD } 2000 \text { P }\end{array}$ & Q. TYPE OF REPOAT AMD PERIOD COVERED \\
\hline \multicolumn{2}{|l|}{ 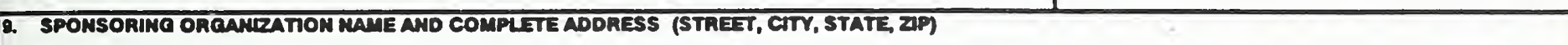 } \\
\hline \multicolumn{2}{|l|}{$\begin{array}{l}\text { National Institute of Standards and Technology } \\
\text { Computer Systems Laboratory } \\
\text { Computer Security Division } \\
\text { Gaithersburg, MD } 20899\end{array}$} \\
\hline
\end{tabular}

10. SUPPLEMENTAY NOTES

11. ABSTRACT (A 200-WOAD OA LESS FACTUAL SUMMARY OF MOST SIONIFICANT IMFOAMATION. IF DOCUMEAT IMCWDES A SIOMIFICANT BUBLOORAPHY OA UTERATURE SUAVEY, MEMTION IT HERE)

The Secure Data Network System (SDNS) project, initiated by the National Security Agency in 1986, produced a computer network security architecture within the framework of the International Organization for Standardization (ISO) reference model for Open Systems Interconnection (OSI). The security protocol at layer 4 (SP4) is one element of the SDNS architecture used to provide security services at the Transport Layer of the OSI reference model. This report specifies the Protocol Implementation Conformance Statement (PICS) proforma for SP4. When the PICS proforma is completed for an SP4 implementation, it provides a clear and concise statement of capabilities, useful in a variety of situations to those involved in the production, testing, supply, procurement, and application of the implementation.

12. KEY WORDS (6 TO 12 ENTRIES; NPHAEETICAL ORDER; CAPTALIZE ONLY PROPER MMMES; ANO SEPARATE KEY WOADS DY SEMICOLONS)

Computer Network Security; Open Systems Interconnection; Protocol Implementation Conformance Statement; Secure Data Network System; Security Protoco1

13. AVALABIUTY

$\mathrm{X}$ unumertas

FOR OFFCNL DISTRILUTION. DO NOT REEASE TO MATIOML TECHNICNL MFORMATION SERVCE (MTSS).

ONDEA FROM SUPERINTENDEMT OF DOCUMENTS, U.S. OOVERNMENT PRIMTING OFFICE, WASHINOTON, DC 20402

OADER FHOM MATIONAL TECHNICAL INFOAMATION SERYCE (MTIS), SPRINGFIEU, VA 22161.
14. MUMBER OF PRIHTED PACES

23

15. PAICE

$\mathrm{AO} 2$ 


